\title{
Una mirada sobre las independencias americanas: el ideario político de Joaquín Infante, de lo local a lo continental ${ }^{1}$
}

\author{
por \\ Leida Fernández Prieto \\ Instituto de Historia, CCHS-CSIC
}

\begin{abstract}
Este artículo explora la influencia de distintos procesos políticos en el pensamiento y el itinerario independentista de Joaquín Infante durante las revoluciones liberales de comienzos del siglo XIX, en particular su ideario sobre Cuba, su patria local, y la América continental española. Para ello se divide el texto en tres apartados. En el primero se mencionan las influencias de la revolución de Haití, el vínculo con las logias francmasónicas y su participación en Caracas en las luchas por la emancipación de España en la configuración de su pensamiento proindependentista. En el segundo apartado se analiza la primera Constitución de Cuba escrita por Infante. En el último apartado, se estudia el texto escrito por Infante en 1820 que refleja la posición de España frente a los procesos emancipadores de América.

Palabras clave: independencias americanas; España; Cuba; Joaquín Infante.
\end{abstract}

\section{INTRODUCCIÓN}

A finales de 1825 el criollo bayamés Joaquín Infante arribaba de forma clandestina al puerto de la Habana procedente de México. Las autoridades coloniales advertían de la llegada del «peor revolucionario que puede pisar suelo cubano». A partir de este año, sin embargo, se desconoce la última etapa del protagonista de una intensa y compleja historia de vida marcada por la participación en las conspiraciones francmasónicas, en los intentos de

${ }^{1}$ Trabajo dentro del proyecto HAR2012-37455-Co3-01, financiado por el Ministerio de Economía y Competitividad, y RYC-2009-04030. 
sublevaciones y en las luchas por la emancipación americana, de huidas, de prisiones y de exilios en la era de las denominadas revoluciones atlánticas de finales del siglo XVIII y comienzos del siglo XIX. Tal cadena de acontecimientos justificaba el citado temor de los funcionarios coloniales, a los que se añadían epítetos tan diversos como, por ejemplo, «segundo Robespierre», «personaje romántico»y «hombre-mito» ${ }^{2}$. Algunos autores sitúan a Infante en Cartagena en diciembre de 1826 al escribir una carta dirigida a Simón Bolivar $^{3}$. En cualquier caso, la ausencia de evidencias certeras alrededor de los últimos años de su trayectoria vital resultan cuando menos inquietantes, si tenemos en cuenta la estrecha vigilancia de las autoridades españolas.

Con frecuencia los estudios destacan la singularidad de que Cuba se mantuviera bajo el dominio de España durante los procesos emancipadores americanos por el interés de los hacendados azucareros para asegurar el vacío dejado por la Revolución de Saint-Domingue (1791) y, sobre todo, el supuesto temor de los criollos y peninsulares al contagio de la revolución ${ }^{4}$. Desde esta perspectiva, Cuba y Puerto Rico son la excepción americana al no sumarse al movimiento por la independencia de la América española. Esta visión, no obstante, silencia otras opciones políticas dentro del complejo mundo americano del tránsito del siglo XVIII al XIX. Por un lado, las ideas independentistas circulaban con bastante facilidad entre redes y en la prensa; por otro, existieron sublevaciones contra el orden, incluyendo las «varias revueltas contra la esclavitud», coincidentes con las luchas por la emancipación americana ${ }^{5}$.

Dentro de la reciente eclosión de estudios sobre las independencias americanas, se analizan los movimientos a favor de la emancipación como procesos atravesados por circunstancias, ambigüedades y tensiones que influyeron en el resultado final ${ }^{6}$. Bajo este punto de vista, está claro que la elite azucarera habanera presionó para que la opción colonial fructificara, pero ello no implica aseverar que el movimiento por la independencia no encontró cabida en Cuba. De hecho, la coexistencia de otras opciones políticas favorables a las ideas ilustradas y reformistas liberales que evolucionaron hacia la defensa y

2 Santovenia y Key-Ayala, 1929. Llaverías, 1930. Lazcano y Masón, 1974: 93-118. García Laguardia y Pantoja Morán, 1975. Pichardo, 1977: 253-266. Bernal, 1994. Gómez Castells, 2011: 259-269.

3 Morán, 1975. Gómez Castells, 2011: 259-269.

${ }^{4}$ Moreno Fraginals, 1978. Kuethe, 1998: 209-220. González-Ripoll, Naranjo Orovio, Ferrer, García Rodríguez y Opartny, 2004. Piqueras Arenas, 1999: 129-139; 2002: 465-483; 2005a: 183-206; 2005b. Balboa y Piqueras, 2007. González-Ripoll y Álvarez, 2009. GonzálezRipoll, 2005b: 343-364; 2012: 223-261. Ferrer, 2009: 105-116. Naranjo Orovio, 2013: 67-90.

${ }^{5}$ Franco, 2010: XIII.

${ }^{6}$ Breña, 2014. 
la lucha por la emancipación de Cuba y de la América continental española matiza esta tesis y refleja una sociedad colonial menos homogénea y también menos explorada por los estudiosos. El proyecto de Joaquín Infante es prueba de ello.

Para Cuba, Infante es importante porque fue autor de la primera constitución de vocación independentista. Aún así, el desconocimiento de su figura se refleja en las inexactitudes sobre su trayectoria revolucionaria no siempre cotejada con fuentes documentales. Algunos estudiosos señalan, por ejemplo, que participó en 1817 en la expedición del general Francisco José Mina con el cargo de Auditor de la División Auxiliar de la República Mexicana ${ }^{7}$. Otros autores, en cambio, mencionan que en ese entonces se hallaba o bien en la Habana o preso en Ceuta ${ }^{8}$. Los años entre 1818 y 1820 son, precisamente, los menos conocidos de este bayamés.

Los biógrafos de Infante analizan el proyecto de Constitución sobre Cuba más que el contexto en el que se formó y actuó políticamente a lo largo de su vida. No obstante, Infante fue testigo en Santo Domingo y en Cuba del impacto de la Revolución haitiana que culminó con la independencia de Francia, de las luchas por la emancipación americana y de las propias contiendas del liberalismo en España, procesos que influyeron y moldearon su pensamiento político independentista de lo local a lo continental, pero también de América a Cuba.

Este artículo explora la influencia de distintos procesos políticos en el pensamiento y el itinerario independentista de Infante durante las revoluciones liberales de comienzos del siglo XIX, en particular su ideario sobre Cuba, su patria local, y la América continental española. Para ello se divide el texto en tres apartados. En el primero se mencionan las influencias de la revolución de Haití, el vínculo con las logias francmasónicas y su participación en Caracas en las luchas por la emancipación de España en la configuración de su pensamiento proindependentista. En el segundo apartado se analizan algunos puntos importantes de la Constitución que reflejaban otra manera de pensar el autogobierno de Cuba. En el tercer y último apartado, se estudia el texto escrito y publicado por Infante en Cádiz en 1820, al inicio del trienio liberal, en los que valoraba la posición de España frente a los procesos emancipadores de América.

\footnotetext{
7 Ver la nota 2.

8 Expediente de Joaquín Infante, Archivo General de Indias, Sevilla (AGI), Ultramar, legajo 22 y legajo 339, fs-652-656. María del Carmen Barcia ha cuestionado la veracidad de algunas de las acciones asociadas a Infante, en particular las relacionadas con su presencia en México. Barcia, 2011.
} 
JOAQUÍN INFANTE ENTRE 1796 y 1812

Entre 1796 y 1812 existen, al menos, tres acontecimientos trascendentales para la conformación del pensamiento político independentista de Infante. Nos referimos al impacto en él de la Revolución de Saint-Domingue, a su participación en la conspiración francmasónica denominada Román de la Luz (1809-1810), así como su intervención desde 1810 hasta 1812 en el movimiento liderado por Francisco de Miranda en Caracas hasta su rendición y el posterior encarcelamiento de Infante. Fue en Caracas donde redactó el proyecto de Constitución para Cuba.

Joaquín Infante Infante nació en Bayamo, ciudad situada en el extremo sureste cubano, en enero de 1775 sin que se conozca el año de su fallecimiento ${ }^{9}$. Provenía de una familia de propietarios tabacaleros. En 1796, Infante se graduó de Abogado en Santo Domingo, profesión que ejerció hasta 1804 de forma indistinta en el citado lugar, en su ciudad natal de Bayamo, así como en Santiago de Cuba y Puerto Príncipe. Por tanto, Infante, como otros criollos cubanos, fue testigo presencial de la radicalización de la Revolución haitiana y de su impacto en Cuba. Ada Ferrer destaca, por ejemplo, la relativa facilidad con que circuló por todo el territorio cubano la declaración de la independencia haitiana firmada por Dessalines el 1 de enero de $1804^{10}$.

A ello hay que añadir que el extremo oriental del territorio de Cuba es la parte más cercana a Santo Domingo, hoy República Dominicana, y a la actual Haití, lo que posibilitó la mayor presencia de refugiados franceses. No extraña, pues, que Infante entrara en contacto con las ideas reformistas liberales de los francmasones, pero también conoció lo que representaría «una revolución de esclavos» para Cuba ${ }^{11}$. Aún así, el miedo al contagio no fue un factor paralizante para sus acciones proindependentistas.

A partir de 1807 Infante se estableció en la Habana y ejerció como Agente fiscal de Hacienda en La Habana hasta 1810. A finales de ese año su nombre salió a la luz en calidad de integrante de la denominada conspiración de raíces francmasónicas de Román de la Luz, tío de José de la Luz y Caballero. Para algunos estudiosos dentro de la conspiración coincidieron dos movimientos, una conspiración real de pardos siguiendo el ejemplo de Haití y, de forma paralela, se desenvolvía una acción promovida en círculos masónicos para el establecimiento de una junta similar a la de Sevilla, tras la invasión de los

\footnotetext{
${ }^{9}$ Los datos más precisos sobre su vida en: Portuondo, 2008; 2009: 11-52. Barcia, 2011. Gómez, 2011: 259-269.

${ }^{10}$ Ferrer, 2004: 201; 2015.

11 García Rodríguez, 2003; 2004: 233. Childs, 2006. Barcia, 2008.
} 
franceses y la crisis de la monarquía hispánica ${ }^{12}$. Efectivamente, dentro de la composición heterogénea de los integrantes de la conspiración, se encontraban figuras que luego fueron cabecillas de importantes sublevaciones de esclavos como, por ejemplo, José Antonio Aponte ${ }^{13}$. También entre los pocos esclavos que fueron entonces encarcelados se hallaba Laureano Infante, el calesero de Infante.

Es indudable que esta conspiración merece un estudio más profundo que escapa a estas páginas. Los documentos hablan de «conmoción popular pero que no ha logrado realizarse y el vecindario está en tranquilidad». Es de destacar, sin embargo, que Infante sostenía en la introducción del proyecto de Constitución que fue en el transcurso de este conato que formuló algunas ideas de reforma para Cuba.

Malogrado el conato que dio motivo a este Proyecto, a lo menos me lisonjeo haber procurado la regeneración de mi Patria, y espero todavía que pueda servirle, si la Providencia se digna facilitar una empresa la más conforme a sus altos designios, por más que los tiranos se opongan ${ }^{14}$.

Valdría la pena preguntarse las razones que llevaron a Infante a concebir estas ideas y en qué medida fue influido por los líderes de la conspiración dada la sofisticación de los proyectos barajados como el posible autogobierno de la isla. Es decir, Infante, aún queriendo mantener la esclavitud, tenía muy claro su deseo independentista que se radicalizó con la participación de la revolución en Caracas, sobre todo al lado de Miranda.

La documentación indica que fueron los líderes del movimiento quienes delataron la intentona a las autoridades coloniales, ante el supuesto temor de la sublevación entre los negros ${ }^{15}$. Curiosamente, Infante fue el único que huyó utilizando las redes masónicas. Su primer destino fue Estados Unidos donde se estableció en Nueva Orleans durante un mes. Posteriormente pasó a Caracas a las órdenes de Francisco de Miranda quien le recomendó para el cargo de Auditor de Guerra y Marina de Puerto Cabello, cargo en el que coincidió con Simón Bolívar. Los contemporáneos señalaban que las acciones de Infante en esos años merecieron la ganada fama de revolucionario exaltado bajo el seudónimo de «Segundo Robespierre» ${ }^{16}$.

12 Según José Luciano Franco, los cabecillas Román de la Luz, Infante y Bassave aparecieron como dirigentes de un movimiento político encaminado a lograr la independencia de Cuba gestado en el seno de la logia masónica habanera. Franco, 1977. Barcia, 2011.

13 Franco, 1963. Childs, 2006. Palmié, 2002. Hernández, 2005. Pavez Ojeda, 2011: 283-296.

${ }^{14}$ Infante, 1974: 93.

15 Expediente de Joaquín Infante, AGI, Ultramar, leg. 339, fs-652-656. Barcia, 2011.

16 Ibidem, fs-653. 
Infante fue hecho prisionero tras la rendición de Miranda y enviado a la Habana para que lo juzgaran por la causa de la conspiración de 1810 y su proyecto de Constitución. De ambas causas fue absuelto pero, en Puerto Príncipe se le juzgó nuevamente en 1814 por pertenencia a las logias francmasónicas. Fue entonces trasladado a la prisión de Ceuta.

INFANTE Y SU PROYECTO DE CONSTITUCIÓN PARA CUBA, LA «PATRIA» LOCAL

El proyecto de Constitución para la isla de Cuba fue escrito por Infante entre 1810 y 1812 en el contexto que los historiadores han dado en denominar «eclosión de constituciones» ${ }^{17}$. Se publicó en Caracas en 1813. Parece ser que a la isla debió llegar en los papeles del juicio pero, fue censurado.

El proyecto de Infante estuvo perdido hasta la primera mitad del siglo XX que el historiador venezolano Santiago Key-Ayala lo encuentra a petición del bibliógrafo cubano Carlos M. Trelles ${ }^{18}$. A partir de ese momento el texto es objeto de creciente interés por parte de juristas e historiadores.

Dentro de los diferentes estudios que ha suscitado este escrito, hay tres historiadores con los cuales coincido con sus opiniones generales desde diferentes enfoques. Para Charles Minguet la Constitución de Infante fue importante: «no sólo por la época en que fue redactada. La ideología que en ella se expresa perduró muchos años; es la misma del "reformismo liberal" cubano hasta la guerra de los diez años» ${ }^{19}$. Para Josef Opartný, Infante por este Proyecto es, antes que Félix Varela, el precursor del independentismo en $\mathrm{Cuba}^{20}$. Para Dominique Soucy, el Proyecto fue:

una interesante manifestación del pensamiento masónico liberal de principios del siglo XIX: el de los liberales divididos entre unos conceptos humanistas y de progreso y el mantenimiento de sus intereses políticos y económicos propios de su condición de criollos ${ }^{21}$.

En este artículo se destacan algunos puntos que reflejan la experiencia política hasta entonces de Infante adaptada a la sociedad colonial cubana de

${ }_{17}$ Infante, 1974. Berruezo León, 1986. Álvarez Cuartero y Sánchez Gómez, 2005. Portillo Valdés, 2006. Chust, 2007. Pérez Garzón, 2008. Chust y Frasquet, 2009. Fernández Sebastián, 2012.

18 Santovenia y Key-Ayala, 1929.

19 Minguet, 1972: 62-63.

20 Opartný, 2004: 326-328. No obstante, los estudiosos consideran a Félix Varela como el padre fundador de la corriente independentista en Cuba. Torres-Cuevas, Ibarra y García, 1991. Ibarra, 2004. Piqueras Arenas, 2005b. Rojas, 2010.

21 Soucy, 2006: 62-63. 
inicios del siglo XIX. El proyecto constaba de 100 artículos agrupados en diez títulos denominados: del Estado, del Poder legislativo, del Poder ejecutivo, del Poder judicial, del Poder militar, de la Administración de Rentas, de la Religión, Disposiciones relativas a los funcionarios públicos e individuos del Culto, de la revisión de la Constitución y Disposiciones Generales. Se acompañaba, además, de Introducción, Advertencia y notas aclaratorias cuando lo estimó oportuno.

Desde el punto de vista doctrinal, Infante fue representante de las ideas de la Ilustración y del pensamiento liberal reformista. Sus fuentes fueron muy diversas desde las diferentes constituciones del período como, por ejemplo, la francesa, la de Haití, la de Estados Unidos, así como el Contrato Social de Rousseau, la Declaración de los Derechos del Hombre, etc. Según qué aspecto quería destacar, mencionó en las notas el modelo o las ideas en las cuales se apoyó. Por ejemplo, defendió para Cuba una república esclavista siguiendo el modelo de Estados Unidos. En la Introducción Infante justificaba el Proyecto porque:

tras los sucesos de España, la Isla de Cuba tenía igual derecho a los demás países de América para declarar su libertad e independencia y elegir entre sus habitantes quienes la gobiernan en sabiduría y justicia, impidiendo a un mismo tiempo los males de la anarquía y del despotismo que se hacen sentir hoy con más fuerza que nunca (...) El amor a mi Patria me hizo trabajar el Proyecto de Constitución que sigue, y que creo el más acomodado a los intereses de tan precioso territorio ${ }^{22}$.

Dentro del proyecto de Infante, el aspecto militar cobró particular relevancia al extremo de convertirlo en el cuarto poder (junto a los poderes Legislativo, Ejecutivo, Judicial). Esta decisión la justificó porque

me ha parecido conveniente hacer de ella un Poder distinto en una Isla, que pudiendo ser invadida por muchos puntos excéntricos en una pequeña latitud, y agitada en los de fortificación, concurrencia o agricultura, es preciso dedicarse a su defensa exterior, y a su conservación interior ${ }^{23}$.

Infante aludía a la posición geoestratégica de la isla que había sido objeto de disputas entre las potencias imperiales. Fue más explicito a la hora de exponer su concepto de "Americanos blancos naturales», aquellos en los que descansaba la soberanía de Cuba, el ejercido del voto y de los poderes ${ }^{24}$. En este punto tenía muy presente el conflicto de intereses entre criollos y peninsulares en el contexto de los procesos de emancipación. Para Infante los peninsulares debían estar excluidos por «la oposición de intereses y sen-

\footnotetext{
22 Infante, 1812: 93.

23 Ibidem: 95.

24 Ibidem: 96.
} 
timientos y aun de pasiones que necesariamente ha de asistirles respecto a nuestra emancipación ${ }^{25}$.

Al igual que muchos próceres, Infante utilizó Haití como contra-ejemplo de los movimientos por la independencia ${ }^{26}$. El temor a la influencia de la revolución Haitiana también estaba presente al recordar los acontecimientos en «Surinam, las costas de la Guayana holandesa, las islas francesas de barlovento, en Santo Tomás y Curazao, Jamaica, en la Carolina, Georgia, Nueva Orleans y aún los movimientos con que ha sido amenazada la isla de Cuba» ${ }^{27}$. Evidentemente se refería a los ecos de la Revolución de Haití en las otras islas antillanas y las sublevaciones que, con mayor o menor éxito, habían ido sucediéndose a lo largo de estos años. Precisamente en este temor a las sublevaciones radicaba la «conservación interior» de la que debía encargarse el poder militar. Aún así, en su movimiento participarían esclavos, incluido su calesero y Aponte.

Infante también fue partidario de la esclavitud aplicada a la agricultura porque constituía la fuerza de trabajo y la prosperidad para América. Aquí volvía a mencionar la constitución de Estados Unidos ${ }^{28}$.

Por último es interesante la utilización de los frutos de la tierra, en particular del tabaco, para la formulación de aspectos identitarios que luego fueron retomados por el pensamiento reformista a finales del siglo XIX y, más tarde, en el siglo XX por intelectuales cubanos de la talla de Fernando Ortiz y su conocido Contrapunteo cubano entre el tabaco y el azúcar, cuestión que ha sido analizada por Consuelo Naranjo en diferentes textos ${ }^{29}$. Asimismo, la división que estableció Pérez de la Riva de la Cuba A y la Cuba B donde Infante justo representaba ésta última noción al proceder del oriente del país $\mathrm{y}$, además, de una familia tabacalera.

El proyecto tenía otros muchos aspectos interesantes como, por ejemplo, la libertad del comercio, la tolerancia de la religión, entre otros que escapan a estas páginas. Tras su encarcelamiento y traslado a Ceuta se vuelve más confusa su trayectoria. Lo cierto es que la documentación de archivos y la publicación de un folleto lo sitúan en Cádiz en 1820. Esta publicación recoge su idea de la América española continental. Es una especie de testamento político abiertamente independentista e inclusivo. Prueba de ello fue el tratamiento a la revolución anticolonial de Saint-Domingue.

25 Idem

26 Breña, 2014: 51.

27 Ibidem: 96.

28 Infante, 1812: 115.

29 Ibidem: 117. Ortiz, 1963. Naranjo Orovio y Puig-Samper, 1999: 197-226. Naranjo Orovio, 2005: 153-174; 2013. 
EL IMPERIO ESPAÑOL Y EL MUNDO COLONIAL AMERICANO EN EL PENSAMIENTO CONTINENTAL Y ATLÁNTICO DE INFANTE

En 1820, al inicio del Trienio Liberal, Infante publicó en Cádiz su texto Solución a la cuestión del derecho sobre la emancipación de América ${ }^{30}$. El bayamés fue indultado por las Cortes españolas en 1820.

Si la Constitución ha merecido atención, este texto, en cambio, ha pasado desapercibido. Sorprende la ausencia de estudios, sobre todo porque es el corolario de su pensamiento político independentista de la América española continental. Desde la historia atlántica es interesante valorar este texto porque es un retrato de las sociedades española y americanas y un ejemplo de circulación de ideas a ambos lados del Atlántico. Lo escribió luego de ser indultado por las Cortes el 12 de septiembre de 1820. Este escrito además alcanzó mayor difusión que su Constitución. En 1821 se publicó en México y en 1822 en Caracas.

A lo largo de veinte páginas, agrupadas en dos grandes temas: razones filosóficas y razones políticas, Infante retomó algunas de las ideas señaladas en el proyecto de Constitución sobre Cuba para justificar la independencia de la América española. Así, insistió en el vacío de poder existente en España tras la invasión de los franceses y, a ello, añadía el capital intelectual presente en América para emanciparse del imperio español:

Al invadir los franceses la península, casi todas las provincias de América sin poderse poner de acuerdo por las distancias, dieron un mismo y simultaneo grito porque tenían luces, madurez y consistencia que producen inevitablemente la emancipación ${ }^{31}$.

Entre las razones filosóficas también defendía la tesis de que «la demarcación política ha de arreglarse a la demarcación física» ${ }^{32}$. En este sentido justificó la superioridad de América frente a España y, por ende, la necesidad de que se independizara en cuestiones de carácter geográfico y físicos (el vasto océano que las separaba, la mayor extensión territorial de América, la mayor población en las colonias y su mayor riqueza en recursos naturales).

Fue también muy claro a la hora de plantear que España debió otorgar las autonomías como paso previo a la emancipación, ya que tras ocho años de violencia, tanto de los criollos americanos como de los peninsulares, aún no había sido solucionado. Entre otras razones expone la violencia

\footnotetext{
30 Infante, 1820.

31 Ibidem: 6.

32 Ibidem: 4.
} 
de la conquista, el exterminio de los indígenas y la sustitución por los «negros» de África que fue remediar un mal con otro igual o peor por sus consecuencias, que España no había aprovechado los productos extraídos de América, la poca prosperidad de las colonias hispanas mientras los puntos abandonados por menos útiles (es decir las denominadas Antillas menores) habían florecido incomparablemente en manos de los extranjeros por la dulzura de administración o por su emancipación oportuna ${ }^{33}$. Es decir, se hacía eco de tópicos bien conocidos de la Leyenda negra que acompañó la expansión imperial española.

Infante intentaba instrumentalizar jurídicamente la independencia de América con España como garante constitucional:

Las circunstancias hacen caer de los derechos; y una emancipación que la necesidad, la razón y las conveniencias recíprocas exigen, no es una enajenación gratuita u onerosa hecha por antojo o capricho, que es lo que se quiso precaver en la constitución actualmente en vigor ${ }^{34}$.

Tampoco veía extraño que las colonias se independizaran cuando «los imperios más opulentos desaparecen como el humo y las naciones se suceden de tiempo en tiempo» ${ }^{35}$. En este sentido, invocaba también la patria potestad para determinar la mayoría de edad justa para alcanzar la emancipación: «¿no es justo que esta madre patria la emancipe ya, otorgándole la nacionalidad a que está destinada, si quiere que se diga que sus miras, lejos de ser odiosas, son benéficas respecto a sus hijos allende de los mares» ${ }^{36}$ ?

El monopolio comercial fue criticado por Infante y les culpó de los problemas del declive del imperio español:

Los comerciantes gritan que se les escapa la América, objeto exclusivo de sus especulaciones, y que no pueden vivir sin que siga uncida al carro de la servidumbre. La nacionalidad, la fortuna y el bienestar de más de quince millones de almas deben, pues, sacrificarse a un puñado de monopolistas a expensas de la sangre de sus hermanos de ambos mundos; tal es la moral que se predica en este siglo de las luces y de filantropía ${ }^{37} ! ! !$

Precisamente, para Infante, la libertad de comercio y el idioma serían las plataformas para normalizar las relaciones entre España y sus (ex) colonias, ya que:

33 Ibidem: 5-6.

${ }^{34}$ Ibidem: 17.

35 Ibidem: 8.

${ }^{36}$ Ibidem: 9-10.

37 Ibidem: 12. 
los españoles tendrán preferencia por razón del idioma, además la posición geográfica de España y sobre todo la de Cádiz destina a este punto a ser una factoría de los géneros de América respecto al resto de la Europa (...) así convendría que se anticipe la época de la emancipación en bien de la humanidad y por utilidad de ambos pueblos, sustituyéndose desde luego relaciones de amistad y de comercio a las de dominación y dependencia ${ }^{38}$.

En cuanto a las ventajas para España recordaba:

Todo el mundo sabe las ventajas que se han seguido a la Inglaterra de la emancipación de sus colonias de Norte-América. Sin gastos de funcionarios, y de una fuerza terrestre y marítima saca toda la utilidad que la preferencia por el idioma, costumbres y origen le da en aquellos países sobre las demás naciones en el comercio, industria y artes, a pesar de las rivalidades nacionales y de la guerra $^{39}$.

No debe olvidarse que se está constituyendo el mercado mundial de productos tropicales.

Francia también fue el modelo a seguir en el orden de los beneficios que España obtendría de la independencia de América, apuntando el resultado exitoso de la primera revolución de esclavos:

... el dato reciente de la Francia con la parte de la isla de Santo Domingo que fue suya y ha tenido que ceder a la gente de color que la defendía, después de perder cien mil hombres más o menos, y de gastar inmensas sumas, entablando al fin mas cuerdamente con aquellos habitantes relaciones mercantiles, útiles a uno y otro pueblo ${ }^{40}$.

Para argumentar las razones políticas acudió al texto del economista Álvaro Flórez Estrada, en calidad de diputado a las Cortes españolas y con su obra Examen imparcial sobre Las disensiones de la América con la España. Hay que recordar que Flores Estrada fue el difusor en España y en América de las ideas de los economistas clásicos ingleses, particularmente de las ideas de Adam Smith. Asimismo, se apoyó en las ideas del padre De Pradt antiguo arzobispo de Manilas y su escrito sobre la revolución de España y sus consecuencias. En este sentido reprodujo partes integras de ambos textos y se declaró totalmente partidario del sistema americano que defendió de Pradt, al tiempo que se hizo eco de la pregunta ¿Qué vendrán a ser esos átomos de colonias insulares, que hacían la riqueza de la Europa durante el sueño de la América ${ }^{41}$ ?

\author{
38 Ibidem: 17. \\ 39 Idem. \\ 40 Ibidem: 13. \\ ${ }^{41}$ Ibidem: 19. Flórez Estrada, 1812. De Pradt, 1820.
}


Concluía entonces:

¿La España, pues, no dará a favor de sus hijos de ultramar el ejemplo de magnanimidad que nuestros hermanos del Norte a los de Luisiana, quienes cedidos por la misma España al emperador de los franceses y comprados a este por aquellos los hicieron en estado independiente?

¡Ojalá sirva de modelo a la nación española y ahorre mayores desgracias ${ }^{42}$ !

\section{Conclusiones}

Este texto se hace eco de las últimas investigaciones sobre los procesos independentistas americanos que subrayan que pudieron tener muchos finales dado la complejidad política y económica en el tránsito del siglo XVIII al XIX. Cuba y Puerto Rico optaron por seguir a sus elites y continuar bajo el status-quo español. Desde esa perspectiva, las dos islas antillanas fueron la excepción americana, pero al igual que las restantes colonias hispanas coexistieron ideas y movimientos a favor de la independencia que han sido menos explorados.

Las ideas reformistas liberales e independentistas que defendía Infante fueron comunes a otros pensadores, en muchos casos líderes de los procesos independentistas. Casi todos bebían de las mismas fuentes doctrinales y fueron fruto de las singularidades de las sociedades locales americanas y de las contradicciones del nuevo proceso. En el caso de Infante fue defender una república esclavista. Su conocimiento intimo de figuras independentistas de trascendencia como Francisco de Miranda y Simón Bolívar radicalizaron sus ideas. Prueba de ello es su último texto escrito en 1820 que puede ser visto como el testamento político en pro de la independencia.

\section{BIBLIOGRAFÍA}

Álvarez Cuartero, Izaskun y Sánchez Gómez, Julio (eds.), Visiones y revisiones de la independencia americana, Salamanca, Ediciones Universidad de Salamanca, 2005.

Balboa, Imilcy y Piqueras, José Antonio (eds.), La excepción americana. Cuba en el ocaso del imperio continental, Valencia, Biblioteca de Historia Social, 2007.

Barcia, Manuel, Seeds of Insurrection. Domination and Resistance on Western Cuban Plantations, 1808-1848, USA, Loussiana State University Press, 2008.

\footnotetext{
${ }^{42}$ Infante, 1820: 20.
} 
Barcia, María del Carmen, Cuba: acciones populares en tiempos de la independencia americana, Matanzas, Ediciones Matanzas, 2011.

Bernal, Beatriz (comp. e intr.), Cuba, fundamentos de la democracia: antología del pensamiento liberal cubano desde fines del siglo XVIII hasta fines del siglo XX, Madrid, Fundación Liberal José Martí, 1994.

Berruezo León, Teresa, La participación americana en las Cortes de Cádiz (18101814), Madrid, Centro de Estudios Constitucionales, 1986.

Breña, Roberto, El imperio de las circunstancias. Las independencias hispanoamericanas y la revolución liberal española, México D. F. / Madrid, El Colegio de México / Marcial Pons Historia, 2012.

Childs, Matt D., The 1812 Aponte Rebellion in Cuba and the Struggle against Atlanty Slavery, Chapel Hill, The University of North Carolina Press, 2006.

Chust, Manuel (coord.), 1808: La eclosión juntera en el mundo hispano, México, FCE-Colmex, 2007.

Chust, Manuel y Frasquet, Ivana, Los colores de las independencias iberoamericanas. Liberalismo, etnia y raza, Madrid, CSIC, 2009.

De la Cuesta, Leonel Antonio, Constituciones cubanas desde 1812 hasta nuestros días, Madrid, Ediciones Exilio, 1974.

De Pradt, M., De la revolución actual de la España, y de sus consecuencias, Valencia, José Ferrer de Orga, 1820.

Fernández Sebastián, Javier (ed.), La aurora de la libertad. Los primeros liberalismos en el mundo iberoamericano, Madrid, Marcial Pons, 2012.

Ortiz, Fernando, Contrapunteo cubano del tabaco y del azúcar, Las Villas, Dirección de Publicaciones Universidad Central de las Villas, 1963.

Ferrer, Ada, "El mundo cubano del azúcar frente a la Revolución haitiana", M. a Dolores González-Ripoll e Izaskun Álvarez Cuartero (eds.), Francisco Arango y la invención de la Cuba azucarera, Salamanca, Ediciones Universidad de Salamanca, 2009: 105-116.

Ferrer, Ada, Freedom's Mirror. Cuba and Haiti in the Age of Revolution, Cambridge University Press, 2015.

Flórez Estrada, Álvaro, Examen imparcial sobre las disensiones de la América con España: de los medios de su reconciliación y de la prosperidad de todas las naciones, Madrid, Imprenta de D. Manuel Ximenez Carreño, 1812.

Fraginals, Manuel Moreno, El Ingenio, 3ts, La Habana, Editorial de Ciencias Sociales, 1978.

Franco, José Luciano, La conspiración de Aponte, La Habana, Consejo Nacional de Cultura, 1963. 
Franco, José Luciano, Las conspiraciones de 1810 y 1812, La Habana, Editorial de Ciencias Sociales, 1977.

Franco, José Luciano (comp.), Las conspiraciones de 1810 y 1812, República Bolivariana de Venezuela, Fundación Biblioteca de Ayacucho, 2010.

García Laguardia, Jorge Mario y Pantoja Morán, David, Tres documentos constitucionales en la América española preindependiente, México, Instituto de Investigaciones Jurídicas, UNAM, 1975.

García Rodríguez, Gloria, "Vertebrando la resistencia: La lucha de los negros contra el sistema esclavista, 1790-1845”, Ma Dolores González-Ripoll, Consuelo Naranjo, Ada Ferrer, Gloria García y Josef Opatrný, El Rumor de Haití en Cuba: Temor, raza y rebeldía, 1789-1844, Madrid, CSIC, 2004: 233-320.

García Rodríguez, Gloria, Conspiraciones y revueltas: la actividad política de los negros en Cuba (1790-1845), La Habana, Editorial Oriente, 2003.

Gómez Castells, Máximo, “Joaquín Infante, desde Cuba hasta México: un mito constitucionalista", Revista Tema y Variaciones de Literatura, 35 (Azcapotzalco, México D.F., 2011): 259-269.

González-Ripoll, Ma Dolores y Álvarez, Izaskun (eds.), Francisco Arango y la invención de la Cuba azucarera, Salamanca, Ediciones Universidad de Salamanca, 2009.

González-Ripoll, Ma Dolores, "Entre la adhesión y el exilio: trayectorias de dos cubanos en una España segmentada (1808-1837)", José Antonio Piqueras (ed.), Las Antillas en la era de las luces y la revolución, Madrid, Siglo XXI, 2005b: 343-364.

González-Ripoll, Ma Dolores, "El liberalismo en Cuba y Puerto Rico (1808-1868)", Javier Fernández Sebastian, La aurora de la libertad. Los primeros liberalismos en el mundo iberoamericano, Madrid, Marcial Pons, 2012: 223-261.

González-Ripoll, Ma Dolores, Naranjo Orovio, Consuelo, Ferrer, Ada, García, Gloria y Opatrný, Josef, El Rumor de Haití en Cuba: Temor, raza y rebeldía, 1789-1844, Madrid, CSIC, 2004.

Hernández, Juan Antonio, Hacia una historia de lo imposible: la Revolución Haitiana y el "Libro de Pinturas" de José Antonio Aponte, Ph.D, University of Pittsburgh, 2005, disponible en: http://d-scholarship.pitt.edu/7245/1/VersionFinal1.pdf (Verificada el 15/6/2015).

Infante, Joaquín, Solución a la cuestión de derecho sobre la emancipación de la América por el ciudadano Joaquín Infante, natural de la Isla de Cuba, Cádiz, Imprenta de Roquero, 1820

Kuethe, Allan, «La fidelidad cubana durante la edad de las revoluciones», Anuario de Estudios Americanos, LV/1 (Sevilla, 1998): 209-220.

Lazcano y Masón, Andrés María, Constituciones de Cuba, Madrid, Editora Cultura Hispánica, 1952. 
Llaverías, Joaquín; Trelles, Carlos M. y Santovenia, Emeterio (introducción y estudios preliminares), Joaquín Infante: Homenaje, La Habana, Academia de la Historia, 1930.

Minguet, Charles, "Liberalismo y conservadurismo en Cuba en la primera mitad del siglo XIX. Contradicciones entre «lo específico y lo general»", Historiografía y Bibliografia Americanistas, 16/1 (Sevilla, marzo de 1972): 62-63.

Naranjo Orovio, Consuelo, "La Historia se forja en el campo: nación y cultura cubana en el siglo XX”, Historia Social, 40 (Valencia, 2001): 153-174.

Naranjo Orovio, Consuelo, "La entronización del miedo: iconos del terror y exclusión en el Caribe tras la revolución de Saint-Domingue", Ottmar Ette, Consuelo Naranjo e Ignacio Montero (eds.), Imaginarios del miedo. Estudios desde la Historia, Berlin, Edition Tranvia, 2013: 67-90.

Naranjo Orovio, Consuelo, "Des patries créoles: des narrations de la terre à Cuba et Porto Rico au siècle XIX”, Sylvie Bouffartigue (ed.), Fruits de la terre. Du produit exotique au symbole patriotique. (Caraïbes hispaniques XVIII-XX), Indigo, Côté femmes éd, 2013: 191-209.

Naranjo Orovio, Consuelo y Puig-Samper, Miguel Ángel, “Fernando Ortíz: Herencias culturales y forja de la nacionalidad", Consuelo Naranjo Orovio y Carlos Serrano (eds.), Imágenes e imaginarios nacionales en el ultramar español, Madrid, CSIC, Casa de Velázquez, 1999: 197-226.

Palmié, Stephan, Wizards and Scientist. Exploration in Afro Cuban Modernity Tradition, Durham, Duke University Press, 2002.

Pavez Ojeda, Jorge, "The Painting of Black History: the Afro-Cuban Codex of Jose Antonio Aponte (Havana, Cuba, 1812), Adrien Delmas and Nigel Penn", Written Culture in a Colonial Context Africa and the America 1500-1900, Cape Town, South Africa, UCT Press, 2011: 283-296.

Pérez Garzón, Juan Sisinio, Las Cortes de Cádiz: el nacimiento de la nación liberal (1808-1814), Madrid, Síntesis, 2008.

Pichardo, Hortensia, Documentos para la historia de Cuba, 3Ts, La Habana, Editorial de Ciencias Sociales, 1977.

Piqueras Arenas, José Antonio "La política de intereses en Cuba y la revolución (1810-1814)", Marta Terán y José Antonio Serrano Ortega, Las guerras de independencia en la América española, Morelia, El Colegio de Michoacán, Instituto Nacional de Antropología e Historia, Universidad Mexicana de San Nicolás de Hidalgo, Instituto de Investigaciones Históricas, 2002: 465-483.

Piqueras Arenas, José Antonio, "Leales en la época de la insurrección. La elite criolla cubana entre 1810 y 1814”, Izaskun Álvarez Cuartero y Julio Sánchez Gómez, Visiones y revisiones de la independencia americana, Salamanca, Ediciones Universidad de Salamanca, 2005a: 183-206. 
Piqueras Arenas, José Antonio (ed.), Las Antillas en la era de las luces y la revolución, Madrid, Siglo XXI, 2005b.

Piqueras Arenas, José Antonio, “Azúcar y comercio en los confines del liberalismo cubano (1808-1814)", Revista Mexicana Del Caribe, 8 (Chetumal, Quintana Roo, 1999): 129-139.

Portillo Valdés, José María, Crisis atlántica. Autonomía e independencia en la crisis de la monarquía hispana, Madrid, Marcial Pons historia, 2006.

Portuondo, Olga, "Los umbrales del constitucionalismo en Cuba, 1808-1812”, Revista Bimestre do Caribe, X/ 19 (Goiânia, Brasil, 2009): 11-52

Portuondo, Olga, Cuba, constitución y liberalismo (1808-1841), Santiago de Cuba, Editorial Oriente, 2008

Santovenia, Emeterio y Key-Ayala, Santiago (estudio preliminar y bibliográfico), Joaquín Infante, Proyecto de Constitución para la isla de Cuba, Caracas, Sesquicentenario de la independencia, 1929.

Soucy, Dominique, Masonería y nación. Redes masónicas y políticas en la construcción identitaria cubana (1811-1902), Santa Cruz de Tenerife, Ediciones Idea, 2006.

Fecha de recepción: 30 de septiembre de 2013.

Fecha de aceptación: 25 de noviembre de 2013.

\section{A perspective on independence movements in Latin America: the political ideology of Joaquín Infante, from local to continental}

This article explores the influence of different political processes in the pro-independence thought and program of Joaquin Infante during the liberal revolutions of the early nineteenth century and, in particular, his vision of his birthplace Cuba and of Continental Spanish Ameri$c a$. The paper is divided into three sections. The first refers to the influence in the development of his pro-independence thought of the Haitian revolution, his links with Masonic lodges and his participation in the struggle for emancipation from Spain in Caracas. The second section analyses Cuba's first constitution, written by Infante. Finally, we consider the text which Infante wrote in 1820 on Spain's position regarding emancipation processes in Latin America.

KEY WORDS: Latin American independence movements; Spain; Cuba; Joaquín Infante. 